regular form. Spreading along the tube is slight and occurs to a distance comparable with the diameter of the tube, in bores of I or $3 \mathrm{~mm}$., and under the conditions named. The deposit consists of dark greenish crystals on the side nearer the mercury, and of red crystals on that nearer the iodine. It forms two coloured bands which are contiguous, but, so it appears, sharply divided by a plane across the axis of the tube. Such regularities are of use in determining the location of the deposit.

The results of these measurements will be published in due course, together with observations on the production and character of the deposits.

I4 Bardwell Road, Oxford, April 23.

\section{Mendelism and Evolution.}

Mr. Julian Huxley's choice of examples in his reply to Mr. Tate Regan, in Nature of April I9, was no doubt made before the announcement of Dr. Annandale's death. In the circumstances $I$ may be permitted to indicate the scope of Dr. Annandale's paper (Proc. Roy. Soc. B, 96, pp. 6o-76) on evolution in the Viviparidæ, and to show that Mr. Huxley's criticism is not altogether relevant.

Dr. Annandale approached the subject from the viewpoint of an ecologist, and to criticise his neglect of "experimental" work is as unnecessary as it would be for any one to reproach Mr. Huxley for his own apparent neglect of ecology. Dr. Annandale advanced no theory-as Mr. Huxley supposes-of evolution, but merely attempted to confirm a hypothesis, which in view of the evidence he had accumulated is entirely justifiable. More than twenty years of first-hand experience of tropical biology led him to the conclusion that environment does affect certain forms of life, and that some inherited characters at least are persistent, an opinion strongly supported by Dr. Kammerer's recent experimental investigations. It is perhaps asking too much if we expect a man already immersed in diverse aspects of science to add Mendelian experiments to his activities.

I think Mr. Huxley will acknowledge this, and the utility of Dr. Annandale's ecological work, even if it does tend to show that the key to a satisfactory explanation of evolution does not lie solely in Mendelism. I would recommend to Mr. Huxley's notice his concluding remarks: "Mendelism is true in some cases; some species produce mutations, but gradual changes also take place under the influence of environment, and are perpetuated. . . . No one formula can express, much less explain, evolution."

A paragraph in Mr. Tate Regan's letter is strikingly applicable to Dr. Annandale's work: " . . . the evidence is clear as to what has happened, and when and where it has happened; there are even indications why; but the problem that remains to be solved is how!"' And who can provide the solution?

London, April 20. Cenric Dover.

\section{Condensation Bands formed during the Explosion of Hydrogen and Air.}

WHEN a mixture of hydrogen and air is exploded in a tube open at one end "water rings" are sometimes formed on the sides of the tube. This phenomenon appears to be familiar to some people, but I have not been able to find any published account of it. The accompanying photograph (Fig. I) shows the formation of these condensation bands during the ex- plosion of a mixture of hydrogen and air in a test tube 6 inches long, the gases being ignited at the open end.

Prof. H. B. Dixon, in his work on the explosion of gases in long tubes closed at one end, has shown that, in the early stages of the explosion, vibrations are set up, and the flame moves with a jerky motion. A good photograph of such an oscillating flame is given in Prof. Dixon's paper (Phil. Trans., I903, Fig. 68). The water condensation would appear to occur at the

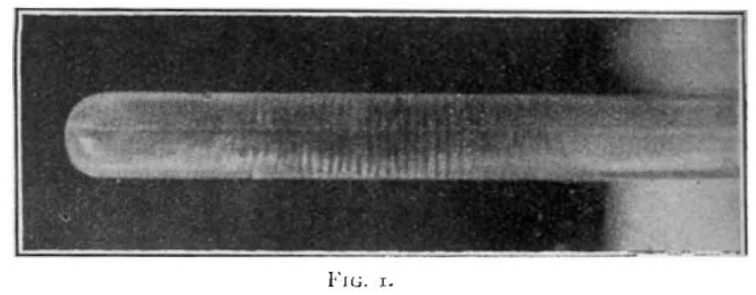

points of most rapid movement, the clear spaces indicating the halting points of the flame. The rings are a little more than I $\mathrm{mm}$. apart at their closest, being wider apart near the open end of the tube. The photograph shows the beginning of the vibratory motion near the open end, the shortening of the swing, and its dying out as the flame approaches the closed end.

Bedford Modern School, Bedford,

G. H. WEST. April 16.

\section{“ Systematic Organic Chemistry."}

THE reviewer of our "Systematic Organic Chemistry" in NATURE of March I5 admits at the outset that the book is conceived on novel lines, and that the design is excellent, but-in proceeding, he makes no attempt to bring either this design or the new text-book matter of the treatise to the notice of his readers; instead, he makes two orthographical corrections, calculates a joke through our omission of a decimal point (see yield of benzaldehyde), and includes other statements to complete what we think a very unfair review.

We believe that our concise account of the use of the library is sufficient to meet the needs of most students, who at any rate will not find the subject even mentioned in any other laboratory manual on the subject in English.

The relative drying power of various substances has been examined by Müller-Erzbach (Ber. I 4, I096), who found that concentrated sulphuric acid, phosphorus pentoxide, and solid potassium hydroxide were almost equal in drying power. It is surprising to us that our reviewer should be "surprised" to find us passing on this little information recorded at such an early date, and made widely known in Smith's translation of Lassar-Cohn's " Manual of Organic Chemistry." In this connexion, why did he omit to state that we quote this remark under the sub-heading- "Drying in Desiccators" ?

The method given for the preparation of diazomethane is the standard method; while backed by the authority of Cain, we give three different methods for the sulphonation of benzene. Again, the reviewer does not mention that methyl iodide (and ethyl iodide) was given under " a general method for the preparation of alkyl iodides " and not as an isolated preparation.

We have the authority of Cohen and of Beckmann himself (Ber. 23, I685) for stating that the yield of benzsynaldoxime is almost theoretical. We are well acquainted with the preparation of $p$-phenetidine, and hence have emphasised the importance of using

$$
\text { NO. } 2846 \text {, VOL. I I } 3]
$$

